acknowledgment of the work of the late Dr. A. v. Krafft, by whom it had been intended that the description of the Triassic rocks should be undertaken.

A chapter is devoted to the correlation of the unfossiliferous sequence of the outer Himalayas with that in Spiti, and an impartial account is given of the guesses-they are nothing more-which have been made, Mr. Hayden does not attempt to deliver judgment on this vexed question, but seems inclined towards Dr. Stoliczka's view; in this we think that he has not taken sufficient account of what may be called extra-Himalayan considerations. The differences between Spiti and the outer Himalayas, the long sequence of fossiliferous rocks in the one, the complete absence of fossils in the other, seem to admit of only two explanations-either the rocks of one area are unrepresented in the other, or the conditions of deposition were so dissimilar that lithological similarity in the two areas is not to be looked for, and either supposition precludes all hope of direct correlation.

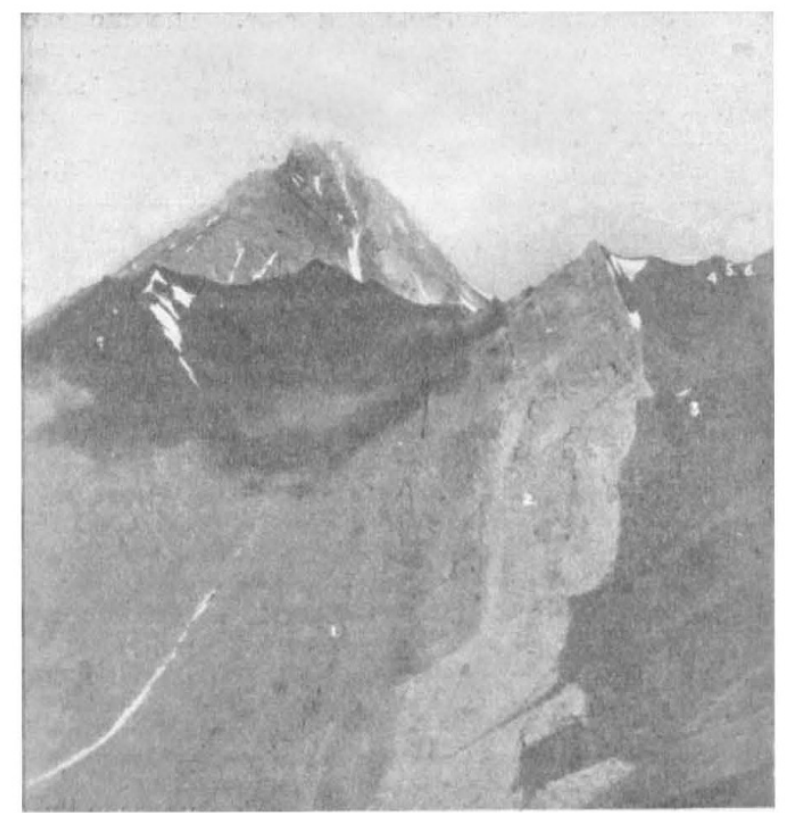

FIG. 1,-Muth Quartzite at Head of Teti River, Bashahır. 6, Daonella Muth Quartzite; 1 , Silurian limestone. From "The Geology of Spiti."

The memoir is indexed and illustrated by plates, several of which are reproductions of photographs by the author; it bears the stamp of careful work, and is worthy of the reputation of the Geological Survey of India. We regret that we cannot say as much for the method of stitching adopted by the Calcutta Government Press; the book may be re-bound, but the torn and mangled leaves can never make a seemly volume.

\section{SIR LAUDER BRUNTON ON THE NEED OF PHYSICAL EDUCATION.}

THE report of the inter-departmental committee on physical deterioration, while in the absence of scientifically ascertained data it hesitated to pronounce the evil it investigated to be widespread, has pointed us all to a better way, and Sir Lauder Brunton in these two addresses drives home the lesson.

I January 5.-National Federation of Head Teachers' Associations, "The Proposed National League for Physical Education and Improvement." January 6. - Incorporated Society of Medical Officers of Health, "The Report of the Inter-Departmental Committee on Physical Degeneration."
In speaking at Cambridge to the Head Teachers Association on the National League, which owes it inception to his statesmanlike grasp of the psycho. logical moment at which to enlist the sympathy anc interest of the nation, half alarmed, half repentant 0 its easy optimism and laissez-faire, Sir Lauder Bruntor went direct to the point-

How can we alter most surely and speedily those conditions which tend to physical deterioration?

The answer lies in a nutshell. By training the young to open-air work and play, to care of teeth ane exercise of muscles, the girls in preparation of appe. tising food, the boys in such drill as will make then real defenders of their country.

We may not go so far as Sir Lauder in his belie: in the educative value of the wall picture of the ravages of the tubercle bacillus-we remember the fearful joy with which we contemplated a ghastly picture o volcanic colouring which an old lady assured us was an accurate delineation of a drunkard's stomach-not do we think his picture of the country cottage altogether accurate; but he has seized the fact thai the master of the situation is the teacher, and to the teacher he turns, confident in his zeal, his devotion his stimulating propaganda, his patient training confident, too, in the plastic material our schools bring to his hand.

To another large class of workers in the public service, the medical officers of health, Sir Lauder Brunton also appeals. He pointed out to the Incor porated Society that physical efficiency is more than doubtful in the mass of people even if physical deterioration is unproved.

For accurate data as to height and weight, growth and physical development of the youth of the nation, we must look to the teachers in daily touch with them. Such data have hitherto been conspicuous by their absence, but once in existence they will enable the statesman and statistician alike to realise the problem they have to solve.

This involves periodical measurement, and to render their task effective the teachers will need instruction, and the most likely person to be called in to give that instruction is the M.O.H. Without trenching on the medical profession the teacher may learn from them to detect signs of fatigue or mental strain, to note defective vision and physical weakness, all of which too often escape notice until irremediable mischief is done.

Sir Lauder Brunton dwelt on the question of the milk supply, the feeding of underfed school children, and the housing question, and warmly endorsed the committee's recommendation that the medical officer of health should have security of tenure in view of the local jealousies he may arouse, the local prejudices he may cross. Discussing the report, Sir Lauder Brunton approved the desire for a Board of Health to undertake some of the duties of the over-worked Local Government Board; failing such a board, he cordially welcomed the idea of an advisory council for matters concerning the national physique, such council to consist of representatives of the Departments of State reinforced by men of science and by experts in questions of health and of physical development.

$\mathrm{He}$ is assured of the readiness of the medical profession to do their part in the educative work; he believes in equal readiness of the teachers to learn and teach what it is of vital importance the coming generation should acquire, not only theoretically, but practical'y - a knowledge of the laws of health.

The National League for Physical Education and Improvement has so far been mainly confined to the medical profession, but now that its aims are focused and defined Sir Lauder looks to a wider public. He 
hopes that before long not only every medical officer of health and every school teacher, but every man and woman who knows what is needed, will join its ranks. Thus will be formed that body of enlightened public opinion which is the moving power in every reform worked, in every advance made by nation, district, or parish, and thus the gospel of physical culture and healthy environment may win its way to every British home. No more patriotic work can be imagined, even though " the foes be they of our own household."

\section{NOTES.}

THE council of the Geological Society of London has decided to award the medals and funds this year as follows :Wollaston medal to Dr. J. J. Harris Teall, F.R.S.; Murchison medal to Mr. Edward John Dunn, of Melbourne; Lyell medal to Dr. Hans Reusch, director of the Geological Survey of Norway; Bigsby medal to Prof. J. W. Gregory, F.R.S.; Wollaston fund to Mr. H. H. Arnold-Bemrose; Murchison fund to Mr. H. L. Bowman; and Lyell fund to Mr. E. A. Newell Arber and Mr. Walcot Gibson.

ST. Margaret's BAy, Dover, where great falls of cliff frequently occur, was the scene of another landslip on Tuesday, January ro, when an enormous slice of the cliff, estimated by the coastguard at about a quarter of a million tons, fell into the sea. The fall occurred a little to the eastward of the bay, where the cliff is about 250 feet high. When the fall took place, about 9.30 a.m., it is said that a very sharp earth tremor was felt throughout the village, and was at first believed to be an earthquake. A further fall occurred at noon. As the result of these landslips a gap about 200 feet wide and 50 feet deep appears in the cliff. The débris at the foot of the cliff covers a large area with some very large fragments of rock. The mass is 20 feet or 30 feet high, and extends seawards about a quarter of a mile.

We learn from the Times that an International Archæological Congress will be opened at Athens by the Crown Prince of Greece on April 7. The opening meeting will be held in the Parthenon, and M. Carapanos, the Minister of Public Instruction, will address the members of the congress. The director of Greek antiquities and the directors of the foreign schools will give an account of the progress of archæological research in Greece. The congress will be divided into seven sections:-(I) classical archæology; (2) prehistoric and oriental archæology; (3) excavations, museums, and preservation of monuments; (4) epigraphy and numismatics; (5) Byzantine archæology; (6) instruction in archæology; (7) geography and topography.

A suIgHr earthquake shock which lasted a few seconds was felt at Gibraltar on January 7 , at 5 a.m. No damage was done. The disturbance was also felt in the Spanish towns of Algeciras, Campamento, and San Roque. At La Linea there were two severe shocks, each lasting about five seconds, the first occurring at 4.40 a.m., and the second at $4.5^{2}$ a.m.

ON Tuesday next, January 17 , Prof. L. C. Miall will begin a course of six lectures at the Royal Institution on the "Structure and Life of Animals." The discourse on Friday, January 20, will be delivered by Sir James Dewar on "New Low Temperature Phenomena," and on January 27 by Dr. E. A. Wilson on "The Life of the Emperor Penguin."

No. I 837 , vor. 7 I]
WE regret to see the announcement of the death of $\mathrm{Mr}$. G. W. Hemming, K.C, in his eighty-fourth year. In addition to contributions extending over many years to various magazines and periodicals, he was the author of a "Differential and Integral Calculus," which appeared in I 848 , and also of a work entitled "Billiards Mathematically Treated" (1893), of which a second edition was recently published.

THE death is announced of Mr. Robert Harris Valpy at the advanced age of eighty-five. Although a keen geologist, he published very little, but he made a very fine collection of fossils from the Devonian rocks of North Devon, and his assistance was acknowledged in the late Mr. Etheridge's work on the "Physical Structure of West Somerset and North Devon" (1867). Mr. Valpy was the author of "Notes on the Geology of Ilfracombe and the Neighbourhood," published anonymously by Twiss and Sons, of Ilfracombe.

THE first award of the Henry Saxon Snell prize will be made this year by the Royal Sanitary Institute. The prize was founded to encourage improvements in the construction or adaptation of sanitary appliances, and is to be awarded by the council of the institute at intervals of three years. The first prize, which will consist of $50 \mathrm{l}$. and a medal of the institute, is offered in the year 1905 for an essay on "domestic sanitary appliances, with suggestions for their improvement." Essays must be delivered on or before March 30, addressed to the secretary of the Royal Sanitary Institute, 72 Margaret Street, W.

THE Association for Maintaining the American Women's Table at the Zoological Station at Naples and for Promoting Scientific Research by Women announces the offer of a third prize of $200 l$. for the best thesis written by a woman, on a scientific subject, embodying new observations and new conclusions based on an independent laboratory research in biological, chemical, or physical science. The theses offered in competition are to be presented to the executive committee of the association, and must be in the hands of the chairman of the committee on the prize, Mrs. Ellen H. Richards, Massachusetts Institute of Technology, Boston, Mass., before December 31, 1906. The prize will be awarded at the annual meeting in April, I907.

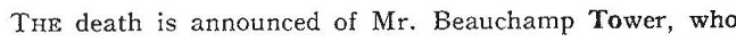
was associated for some years with Mr. W. Froude, F.R.S., in the experiments made for the Admiralty on the models of ships and on full-sized vessels and engines of the Navy, from which experiments much of the present knowledge of the scientific design of ships has been derived. While working as a consulting engineer, says the Times, Mr. Tower developed several ingenious inventions, notably a machine to carry out Mr. Spencer Deverell's idea of obtaining work from wave motion, the well known "spherical" steamengine, largely employed for some years where high rotary speeds were needed, a centrifugal pump revolution indicator for ships, and a gyroscopic steady platform for guns at sea, all of which afford good examples of originality and scientific acumen. $\mathrm{He}$ also undertook for the Institution of Mechanical Engineers, and carried to a successful issue, an extremely complete series of experiments on friction. by which much new knowledge on the subject was gained.

LONDONERS probably began to realise that the electrification of the "underground" railways was nearing completion when, last week, a partial electrical service was started on the section of the lines running from Baker Street to Harrow and Uxbridge. This marks the first step in the change which will be carried out by degrees 